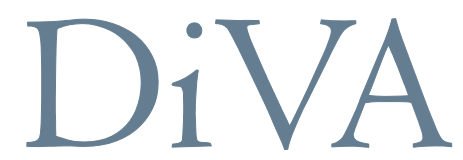

http://uu.diva-portal.org

This is an author-produced version of a paper presented at the 17th Annual Conference of the International Research Society for Public Management; 10-12th April 2013; Prague, Czech Republic.

This paper has been peer-reviewed but may not include the final publisher proof-corrections or pagination.

Citation for the published paper:

Svensson, Emma and Pallas, Josef

"Typical tools for assessment of communicative performance" In:

"Public Sector Responses To Global Crisis: New challenges for politics and public management?" (Proceedings); 2013.

Conference website: http://www.irspm2013.com/

URL: http://urn.kb.se/resolve?urn=urn:nbn:se:uu:diva-203251

Access to the published version may require subscription. 


\title{
Typical tools for assessment of communicative performance
}

Emma Svensson

Department of Information, Technology and Media

Mid Sweden University

$\&$

\author{
Josef Pallas \\ Department of Business Studies \\ Uppsala University
}

\begin{abstract}
Concepts like reputation, recognition, legitimacy, visibility, image, popularity and others are frequently used in describing how successful an organization or its activity has been. In this paper we seek to address some of the concepts used for assessment of political communication and examine what underlying qualities and criteria these concepts refer to. By way of situating our discussion into a broader context of how neo-institutional perspective understands organizational performance we use a two-dimensional framework to identify and illustrate the essential qualities of the most popular concepts. We combine then the different qualities these concepts invoke and suggest a model that can be used in more accurate evaluation of not only (political) communication but also other types of organizational activities.
\end{abstract}

Key words: Political communication, assessment, evaluation, legitimacy, ranking, recognition, status, image, visibility, celebrity, popularity, neo-institutional theory. 


\section{Introduction}

In the world of politics political actors are eagerly competing for attention, interest, engagement and ultimately votes. How to establish what constitutes good (or at least acceptable) political performance is then becoming a critical issue occupying most of those being interested in politics not only as practitioners (i.e., politicians, voters, media, PR-professionals) but also academics within fields like political communication, political science, sociology, organizational research and others. In such a context the political actors are constantly scrutinized, evaluated and judged not only by making themselves assessable with respect to different parts of their activities. They are also subjected to an interest of variety of actors that are - with different motives - involved in production and dissemination of tools, standards and criteria for assessing and evaluating what the political actors say and do (see e.g., Davis, 2005; Hillygus \& Shields, 2009; Lawson-Borders, 2005; Lin, 2011; Lees-Marshment, 2008). These tools - such as ratings, rankings and awards - are often packaged and labeled in audience friendly formats that emphasize simplicity, clarity, generalization and dramaturgy (cf. Grünberg and Pallas 2013; Pallas \& Wedlin 2013). As a consequence we have witnessed an emergence of new ecology of labels and concepts that are used to - in a simple and summative way - describe, indicate and compare the quality of the performance measured. As the professional and experiential judgments from for example consultants, academics and polling institutes such as Gallup or Pew Research Center are mixed with informal and mediated assessments of popular media, interest groups and individuals, these labels and concepts tend not only to be used indiscriminately. They also become blurred and associated with multiple meanings and essentially also consequences. Moreover, the extensive and non-reflexive use and popularization makes the different concepts disassociated from underlying measurement practices and they risk to be used as non-substantive and superficial (however rationalized) evaluations and comparisons (cf. Clegg et al 2004; Mazza 1997). Thus, we may suspect that as the different measures contribute to confusion rather than to clarity on what constitutes a good performance these tools will decline in value (cf. Espeland and Sauder 2007; 
Strathern 1996). An important question that arises concerns how to understand and relate to the different assessment concepts - i.e., what qualities and properties do they signal when applied in labeling social actors and activities.

Concepts like reputation, recognition, legitimacy, visibility, image, popularity and others are frequent in denoting how successful a candidate or a political party was in their campaign. In this paper we seek to address a number of these concepts for assessment of political communication and examine what underlying qualities and criteria these concepts refer to in theoretical terms. Ultimately, such an overview can serve us to outline an analytical framework through which different assessment tools (and their vocabularies) can be classified.

The rest of the paper is organized as follows. First we situate the assessment of political communication into a broader context of audit society where many assessment tools have been proliferated as a way of transforming different qualities into a common metric system (Espeland \& Stevens 1998). Secondly, departing from recent streams of neo-institutional theory we use a two-dimensional framework to identify and illustrate the essential qualities some of the most popular concepts for assessment of political performance/communication emphasize and proliferate. Finally, by combining dominant bases and signals of performance the different concepts invoke we suggest a model that can be used in a more accurate evaluation of political communication.

\section{Background - performance assessment and politics}

The emergence and importance of the different evaluation and assessment tools and activities is usually described by referring to the notion of audit society, i.e., a society where accreditations, standards, rankings, ratings, prices, awards and other forms of measurement have become an integrated part of how we organize and manage a wide range of uncertainties and risks in areas such as politics, economy and sustainability (Power 1997; 2007 see also Brunsson \& Jacobsson 2000, Beck 1998, Power et al. 2009). A recurrent argument in this literature is that such 
instruments - their production, circulation and implementation - function not only as tools by which individual organizations (such as political ones) can be assessed, evaluated and governed. At an aggregated level these instruments create stability and predictability in a given area of the social by signaling what characteristic of an organization are crucial and attractive and how to assure that these characteristics are achieved and/or upheld (cf. Brunsson \& Jacobsson 2000). Thus, performance measurements operate both at the level of organizations and their practices (i.e. organization level), as well as at the level of production of normative ideas about what qualities and virtues are appropriate or desirable (i.e. field level).

These performance measurements can be labeled and associated with concepts like legitimacy, reputation, status, and others (cf. Fombrun \& van Riel 1997; Deephouse \& Carter 2005). The different concepts not only influence knowledge about organization directly through direct evaluation. They have also an indirect effect on organizations by way of changing the organizational and institutional prerequisites for interactions between organizations and their audiences/other social actors (Espeland \& Sauder 2007; Martins 2005). Or differently, rather than seeing these concepts as merely providing information about individual actors, they are central for building normative, regulative, and cognitive bases on which these actors are assessed and evaluated both individually as well as members of an industry or field.

In sociology and organizational research these assessment measurements (and concepts associated with these measurements) have been mainly paid attention to as tools for disseminating and translating different requirements, ideas, and expectations that a wide range of interest groups have on organizations within their relevant fields. John Boli (2006) for example discuss how such dissemination and translation operate in the context of global moral rationalization. Through celebrations (awards, prizes) and certifications (accreditations, technical standards and tests) the global moral norms influence what qualities (virtues) and performance standards (virtuosity) are to be stressed and prioritized in a variety of organizations. Literature on rankings and accreditations (cf. Eslbach \& Kramer 1996; Wedlin 2011; Sauder 2008) illustrates - 
in a similar vein - how those who measure, credential and certify can - by way of offering both relative as well as absolute indicators of quality and performance - shape not only individual organizations but also entire fields of which these organizations are parts of. Yet other streams of research examines how standards - defined as non-coercive prescriptions and rules about what to do and how - are used in assessing and forming three major aspects of organizations, namely 1)

actors' identity, 2) organizational structures and 3) organizational activities (Brunsson et al. 2012, Higgins \& Hallström 2007). As illustrated by Power et al. (2009) discussing reputational risks these aspects constitute a basis on which organizations are evaluated and treated (see also Brunsson \& Sahlin 2000).

In a political context political actors communicative performance are continuously evaluated through out the election cycle with a heighten interest during and after election campaigns. Even though concepts such as popularity, reputation, image and recognition are frequently used in these evaluations there is a lack both of a conceptualization and a discussion about what these really assess. Rather, assessments have been carried out by the help of e.g., models such as Lees-Marshment's (2008) product- sales- or market oriented party, Ormrod's (2005) political market orientation (see also Ormrod, 2007; Ormrod \& Henneberg, 2010) and Gibson \& Römmele’s (2001) professionalization index which measures campaign communication by the use of e.g., opinion pulling, databases, targeting, and continuous campaign (see e.g., Nord \& Strömbäck, 2009; Strömbäck, 2007).

\section{Bases for and signals of performance evaluation}

As the political communication literature lacks a deeper discussion on how the different measurements of political performance are constructed and how they operate we turn to the above mentioned sociological and organizational research to identify some of the fundamental qualities and properties that are used both as bases for as well as signals of acceptable, desirable or admirable behavior or performance. Moreover, these qualities and properties of social actors 
such as politicians or organizations can be understood in relation to two dimensions: a) the level at which bases for performance are defined, and b) by what means performance is expressed. The first dimension signifies whether we can speak of general qualities that are defined in relation (and are applicable) to all or a majority of organizations within a relevant social context or if these qualities are specific for a single or few actors within this context. Applied to political communication this dimension can refer to aspects such as a quality of a speech or a campaign that is evaluated on the basis of fulfilling widely spread expectations on a political act (field level) or as helping a political actor to achieve a specific goal (organizational level).

The second dimension indicates whether an organization is described on the basis of its membership in or association with(in) a widely recognized field or group of other organizations (similarity); or if its performance is related to discriminative technical, financial and moral qualities that are expressed in relative terms rather than categorical ones. Again - translating to political context - does a campaign follow established ways of campaigning, or is there a deviating aspect of communication that contributes to outperforming the opponents?

But before moving to the discussion of different concepts based on the two dimensions, let us shortly examine how assessment and evaluation activities and dynamics are addressed and understood in the traditional neo-institutional writings, i.e., writings that constitute a dominant stream within the existing sociological and organizational research in this area. First and foremost, at which level organizational performance is assessed relates in this literature to the tension between conformity and strategy as the fundamental strategies for success. Conformity being driven by the assumption that successes is based on a generalized perception of an actor as desirable and appropriate only if his/her actions are in alignment with established system of norms, rules values and beliefs (cf. Suchman 1995), collides with the strategy argument that stipulate that positive future outlook of an actor is based in collective perceptions of past performance and in relation to other actors - i.e. being different (cf. Deephouse \& Suchman 2008). The observant reader has noted that while both types of evaluation are based in collective 
and generalized assessments, there is an important different between these two in terms of their ontological status. While strategy is defined at organizational level -i.e., the term denotes performance of an actor in relation to other actors sharing same or similar social contexts, conformity measurements describe and assess organization in relation to relatively stable structures, processes and preferences defined at field/societal level (DiMaggio \& Powell 1983/1991). As the discriminating (strategic) technical qualities are shaped by efforts of individual actors such as competitors, media or different types of consultants they come often in terms of metric and are expected to rank organizations on their ability to be different and competitive (cf. Meyer \& Rowan 1977; Elsbach \& Kramer 1996; Rao 1994). Social norms and values are - on the other hand - generated at the field level by way of coercive, normative and mimetic processes - i.e. processes that are in neo-institutional theory referred to as isomorphism (DiMaggio \& Powell 1983/1991; Scott 2001). These institutional demands emerge through the work of non-hierarchical actors that scrutinize, monitor, and evaluate organizations and their activities, and they operate as a tool for defining the constitutional properties of organizations, i.e. properties that are 'taken-for-granted' and necessary for any organization that whish to be granted the 'license to operate' within a particular context (cf. Brunsson \& Sahlin-Andersson 2000).

\section{The ecology of evaluation concepts}

In the following, we use the above-introduced dimensions to present and discuss some of the frequent concepts that are used in literature on political campaigns to describe and evaluate communicative performance of political actors. We have chosen those that both empirically and theoretically figurate as the most frequent and central. Once again, as there is no coherent research on these concepts within political communication we have turned to organizational and sociological literature, i.e., literature that has been more systematic on this account. 


\section{Legitimacy}

Legitimacy is commonly described as "a general perception or assumption that the actions of an entity are appropriate within some socially constructed system of norms, values, beliefs, and definitions" (Suchman 1995: 574). But already Pfeffer and Salancik (1978) indicated that if we want to understand how organizations receive support from key interest groups like owners, suppliers and customers we need to go beyond technical terms in evaluating organizational performance and pay attention to how these organizations relate to a broader social context of which they are a part of. Such an argument is also central to neo-institutional theory where legitimacy has become a key concept in explaining external foundations of organizations (cf. Meyer \& Rowan 1977). Here it is argued that organizations must act in a manner that is consistent with socially accepted norms and expectations if they are to be seen as legitimate beyond the scope of individual relations with central stakeholders (DiMaggio \& Powell 1983/1991; Suchman, 1995). Legitimacy reflects long-term adaptation of organizations to what is institutionally defined as appropriate, i.e. a quality that has been shown to be directly connected to increased survival rates (Hannan \& Carroll 1992; Ruef \& Scott 1998) conditioned by factors such as access to financial support (Deeds et al. 2004; Pollock \& Rindova 2003) or ability to reduce market risks (Bansal \& Clelland 2004). Legitimacy of an organization is thus directly related to a general evaluation of whether the organization reflects shared values and commonly held beliefs, or if it violates uncertainty-reducing social codes. Since the above mechanisms operates on field/societal level an evaluation of an actor's legitimacy is not so much based on comparison with other actors that share the same or similar institutional context in terms of better or worse. Instead legitimacy reflects actors' ability to behave similarly with actors that are already defined as legitimate.

The mimetic effects of legitimacy are also reinforced by involvement of external actors such as media, consultants and customers that provide their audiences with moral and cultural accounts about the appropriateness and desirability of an organization's actions (Elsbach 1994, 
2006). It is these actors that are core determinants of specific as well as general attitudes towards organizations by way of shaping and presenting people's perceptions through news coverage, providing narratives, production of normative ideas and prescriptions (cf. Carter 2006; Kennedy 2008; Pollock \& Rindova 2003).

\section{Recognition}

Recognition is a concept with many different definitions depending on in which research field it is used. In marketing, advertising and political marketing recognition is commonly used in connection with brands, logos and candidate names (Ahn \& La Ferle, 2008; Henderson \& Cote, 1998; Parker, 2012; White \& De Chernatony, 2002) while name recognition in political science refers to how known a certain political actor is and is thus an important factor in elections. Subsequently, in these fields recognition is seen as a factor used for positioning (Ahn \& La Ferle, 2008). In social psychology, on the other hand, recognition is used to underline the importance of getting recognized by others and in sociology recognition is foremost used in terms of struggles between different groups - "the politics of recognition" (see e.g., Taylor, 1994) and at times to refer to publics' acknowledgment of a person's or an organizations merits. This latter usage seems most viable in the assessment of performativity. Recognition in this sense is closely connected to e.g., Coleman's (1990) notion of social capital, i.e., it works on an individual or organizational level and facilitates a certain activity within an aspect of the social structure. Since these social structures are semi-closed (Lin, 2002), recognition builds on durability and similarity between those who constitute the aspect.

\section{Status}

Weber (1946/1922) described status as a stratification mechanism based on e.g., consumption and occupation and (thus) a specific style of life. Status can be defined as a "socially constructed, intersubjectively agreed-upon and accepted ordering or ranking of individuals, groups, 
organizations, or activities in a social system" (Washington \& Zajal, 2005, p. 284). It is thus a positional and relational element of a social structure based on an agreed-upon social rank logic and not e.g., on merits (Washington \& Zajal, 2005; Weber, 1946/1922). Status is both ordinal and categorical (Deephouse \& Suchamn, 2008) and subsequently rests upon distance and exclusion (Weber, 1946/1922). Consequently, it also reflects cultural capital and habitus (Bourdieu, 1986) and it is those who are on the inside that can select and invite those with a different (often lower) status who are on the outside (Weber, 1946/1922). Status involves a monopolization of e.g., ideals and opportunities (Weber; 1946/1922) and the consequences of a certain status can be described as either privilege or discrimination (Weber, 1946/1922; Washington \& Zajal, 2005).

Competition is the core of status (Benjamin \& Podolny, 1999; Deephouse \& Suchman, 2008; Weber, 1946/1922) and thus distinctiveness. Washington \& Zajal (2005) argues that status can effect an organizations behaviors and outcome irrespective of performance. In consequence, organizations can use status as a strategic tool by e.g., cooperating with organizations or persons with high status as a way to accumulate positive associations (Washington \& Zajal, 2005). The other way around is however also common, that the actor is associated with actors with lower status, which might lead to an "accumulation of negative associations" (Washington \& Zajal, 2005). These associations may have several consequences. One is that e.g., claims made by an organization with high-level affiliations are more likely to be considered credible and trustworthy than similar claims made by low-status affiliation (Benjamin \& Podolny, 1999). Another, and closely connected with the former, is that the evaluation of performance is not only based on the actors own status but also the status of those actors that it is associated with.

\section{Reputation}

Reputation is a generalized collective perception on an aggregated level of an organization that includes expectation about its future behavior based on its past. In corporate commnication reputation is foremost portrayed as something that, through purposeful and strategic 
communication can be treated, managed and cultivated by the organization. Brønn (2010, p. 745) defines reputation management as "the strategic use of corporate resources to positively influence the attitudes, beliefs, opinions, and actions of multiple corporate stakeholders including consumers, employees, investors, and the media". Defined in this manner it first of all imply that the organization can manage publics perceptions, and secondly that this activity aims at all different publics, both those who are close (e.g., members) and those who are more distance (e.g., voters).

Another way to define reputation is that it is an answer to the question of what publics' thinks of the political organization. It is formed outside the organization by publics on the basis of subjective impressions (L'Etange, 2006), and is thus a representation. Reputation is often expressed through rankings, i.e., it is an objectified and rationalized measurement and thus experience based. In other words, reputation is something constructed consisting of publics interpretations of the organizations history, its accomplishments and potential future (Christensen et al., 2008). Reputation is consequently a basis for differentiation (Bartlett et al., 2013; Deephouse \& Carter, 2005) as well as a tool for positioning the political organization on the political map of ideology, issue positions etc., and thus facilitating ranking between them.

\section{Popularity}

Even though "popularity" is a frequently used concept in assessment and evaluations of political actors and their communication, hardly any conceptual attention has been given to it. Turning to research fields in which there have been some attention given, those who define popularity tend to rely on definitions given by dictionaries (see e.g., Scott \& Judge, 2009). Following this “tradition”, the Oxford English Dictionary (2005) defines popularity as "generally accepted, commonly known", while Merrian-Webster's Collegiate Dictionary (2003) defines it as "frequently encountered or widely accepted". In educational and workplace psychology popularity is described as a collective perception that reflect a groups feelings (Cillessen \& Rose, 2005) and is a 
general consensus. Popularity follows a simple scheme: the more attention (by a public, media etc.), the more popular and functions as social influence where one effect may be that people do not really reflect on their "choices" and rationale for liking e.g., a politician more than another. Consequently, popularity is a property at the individual or organizational level, changeable and thus a temporal asset.

\section{Visibility}

Even though some equates visibility with presence (Aaker \& Joachimsthaler, 2000;

Joachimsthaler \& Aaker, 1997) in the literature the concept is mostly used in terms of media visibility in the literature (Capriotti, 2009; Fombrun \& Van Riel, 2004; Manheim, 2011). The reason why media is so important is, according to Baker, Powell \& Weaver (1998) based on two aspects. The first deals with media as a facilitator or a channel for the "distribution" of information about the organization, while the second propose that the information that media supply reduces the level of uncertainty about the organization. A study of those organizations with highest ranking in the Corporate Reputation Index by Fortune shows that they are the same as those with highest media visibility (Gaines-Ross, 1997) and thus confirms the importance of media. Visibility in this sense is accordingly associated with identification, i.e., that media visibility facilitate the process where actors get known in the public mind based on a general perception. In addition, several studies show that media visibility constitutes an important influence on the public opinion (see e.g., Deephouse, 1997, 2000; Fombrun \& Shankey, 1990; Fombrun \& Van Riel, 2004). In this sense then, visibility is not democratic but discriminating since some are more visible than others based on e.g., economic and social capital.

\section{Celebrity}

According to Grinin (2009) celebrity should be understood as "a definite kind of more and less widespread information about a person, which in a certain sense distinguish him or her from the 
overwhelming majority of those people who possess the same professional or social characteristic" (p. 1). Celebrity is a differentiating factor within the same status strata (Grinin, 2009; see also Marshall, 1978) and a type of symbolic capital (Bourdieu, 1986). Just like e.g., status, celebrity rests on inequality and is generally seen as a agreed-upon earned position but which at the same time often is based on a "false value" (Marshall, 1997; Monaco, 1978; Rojek, 2001; Turner, 2004). It is consequently binary: you either are a celebrity or you are not. Celebrity is however not only a characteristic of a person but, as Rindova, Pollock \& Hayward (2006) argues, can also be used at the organizational level. They mean that celebrity has two defining characteristic: firstly it attracts large-scale public attention and secondly it elicits positive emotional response (pp. 50-51). As a consequence it may alter the economic opportunities available in a positive direction and when it leads to access to critical resources (e.g., human capital and donations) celebrity can be viewed as an intangible asset to the organization.

Celebrity nowadays is a mediated phenomenon: the notion of celebrity builds on that people in the public sphere knows who the celebrities are (Boorstin, 1961; Grinin, 2009; Marshall, 1997; Rojek, 2001; Turner, 2004) and mass media representation is subsequently a "key principle in the formation of celebrity culture" (Rojek, 2001, p. 12). Celebrity thus arises in a coproduction between media and the public, altering the actor's opportunities in relation to other actors.

\section{Image}

In the literature of corporate communication some argue that "reputation" simply has replaced image (see e.g., Coombs \& Holladay, 2010; Grunig \& White, 1992) whereas others argue that it is a concept with a similar definition as reputation (Hatch, 2008) and contribute to it (Bernstein, 1985; L'Etang, 2006). Both reputation and image is general assessments and function as bases for differentiation between actors. The differences between the concepts can be found in their respectively temporal and spatial dimensions. While reputation is more enduring and have ensued 
during a longer period of time (Gioia, Schultz \& Corley, 2000) thus building on a greater knowledge about e.g., a political actor, image is a more temporary assessment with a greater spatial distance between the object and the public and is - subsequently - based on lesser knowledge. It is thus possible to view image and reputation as a continuum: the more information, knowledge and experience a person gets about a political actor, the closer to reputation s/he gets. Image is consequently foremost mediated.

\section{Towards a multi-dimensional typology of performance assessment}

We have started the paper by arguing that the different concepts used in describing results of evaluation activities of organizational performance - in our case political communication - can be discussed in terms of the qualities and properties that signal and are based in what is socially acceptable, desirable or admirable behavior. The above-presented account has been guided two dimensions: a) the level at which bases for performance are defined; and b) by what means performance is expressed. We argued that the concepts reflect an actor's performance by way of general qualities that are defined at the level of relevant social context; or they indicate qualities of a single or few actors within a given context. The second aspect from which the concept were identified and presented was related to an actor's performance as based in difference from or similarity to other organizations within a widely recognized field or group of other actors.

However, our review has also brought to fore a number of other aspects that differentiate the concepts from each other. Frist, the different concepts vary with their focus on technical or symbolical signals of performance evaluated. Legitimacy, status and visibility as theoretical concepts emphasize generalized perceptions of an actor's performance through abstract and relatively subjective criteria that are not easily expressible in specific and precise technical measurements. These concepts reflect actors' ability to present their commitment to the vague requirements by way of variety of ceremonial expressive means. Formal statements, presentations, general rapports and speeches are just few examples of symbolic material where actors not so much 
present and explain their performance in relation to fixed values and measures. Instead, there is an emphasis on belonging to a category of actors whose performance is already perceived as satisfactory.

Secondly, the concepts have also different temporal underpinning. Whereas some of the underlying performance assessments (legitimacy, status, recognition and reputation) relate to long-term ability of actors to behave in alignment with institutional expectations or secure competitive quality of their products and activities. Visibility, popularity, celebrity and image indicate on the other hand actors' performance through signals that reflect qualities that are more temporal and fluctuate over time.

Finally, there is also a qualitative difference in what material/input is used for performance assessments underlying the concepts. Where the first group of concepts including legitimacy, status, reputation and recognition is connected to assessments that are based on direct, objective and systematic measurements (such as accreditations, official polls, ratings and rankings); the second group - represented by popularity, image, visibility and celebrity - is dependable on anecdotic, subjective and approximate indicators brought mainly by popular media outlets. We summarize the different dimension in figure 1.

Figure 1 to be inserted about here

Noteworthy in this figure is that we lack a theoretical as well empirical concept that would capture an actor's temporal adaptation to field level expectations by way of symbolic representation. An argument that can be used here is that general qualities that are expected to be valid for majority of actors within a specific social context take long time to be formally incorporated into the way the actors identify and describe themselves. Thus, it can be difficult for external audience - to expect formal signals of conformity to shortly lived trends and ideas even if these are generate at the level of entire fields or industries. 


\section{Conclusion}

Underlying this paper was the ambition to outline an analytical framework through which different concepts used for describing qualities of political communication could be classified. We aimed at providing a starting point for clarifying, specifying and demarcating each concept so they would become less interchangeable. The suggested multi-dimensional framework can help us separate the concepts (at least at the conceptual level) from each other so we can avoid using them as all-inclusive representations of a given quality of an actor and her/his activities. Thereby the concepts can be defined (and used) as less holistic as they only describe a specific part or aspect of an actor's performance.

In the realm of political communication or rather the evaluation of political actors communication, this multi-dimensional framework may have several positive implications for future studies of e.g., campaigns. In descriptive studies it can work both as a clarifying tool and offer more nuanced classifications. If scholars are more careful with what they mean with those tools of evaluation that they use, our description of an actor's performance can also be more nuanced. An approach like this could have, at least, two (positive) consequences. It might first of all be a way to reach a better understanding of what drivers and dynamics lies behind these evaluations. Secondly, it may facilitate our understanding of how these concepts contribute through feedback - to an actor's future behavior. 
Figure 1. Bases and signals of performance

\begin{tabular}{|c|c|c|c|c|c|}
\hline \multirow{2}{*}{$\begin{array}{c}\text { Bases for } \\
\text { performance }\end{array}$} & \multicolumn{2}{|c|}{ Durable } & \multicolumn{2}{|c|}{ Temporal } & \multirow{2}{*}{$\begin{array}{c}\text { Signals of } \\
\text { performance }\end{array}$} \\
\hline & Similarity & Distinctiveness & Similarity & Distinctiveness & \\
\hline Field level & Legitimacy & Status & & Visibility & $\begin{array}{l}\text { Symbolical } \\
\text { representation }\end{array}$ \\
\hline \multirow[t]{2}{*}{$\begin{array}{c}\text { Organizational } \\
\text { level }\end{array}$} & Recognition & Reputation & Popularity & Celebrity/Image & Technical \\
\hline & \multicolumn{2}{|c|}{ Experience based } & \multicolumn{2}{|c|}{ Mediated } & \\
\hline
\end{tabular}




\section{References}

Aaker,D. \& Joachimsthaler, E. (2000). Brand Leader. New York, NY: The Free Press.

Ahn, J., \& La Ferle, C. (2008). Enhancing recall and recognition for brand name and body copy. Journal of Advertising, 17(3), 107-117.

Baker, H. K., Powell, G., \& Weaver, D. (1998). The effect of NYSE listing on a firm's media visibility. Journal of Economic and Finance, 22(1), 19-28.

Bansal, P., \& Clelland, I. (2004). Talking Trash: Legitimacy, Impression Management, and Unsystematic Risk in the Context of the Natural Environment The Academy of Management Journal, 47(1), 93-103.

Bartlett J, M. Frostensson \& J. Pallas (2013) "Reputation Rankings, Certifications and Accreditations" in Craig, C. (ed.). Handbook of Communication and Corporate Reputation. New York, Wiley-Blackwell

Beck, U. (1998). Risksambället. På väg mot en annan modernitet. Göteborg: Daidalos.

Boli, J., 2006, "The Rationalization of Virtue and Virtuosity in World Society", in: Djelic, M.-L., Sahlin-Andersson, K. (Eds), Transnational Governance Institutional Dynamics of Regulation, Cambridge: Cambridge University Press, 95-118.

Benjamin, B. A., \& Podolny, J. M. (1999). Status, quality, and social order in the California wine industry. Administrative Science Quarterly, 44, pp. 563-589.

Bernstein, D. (1985). Company image \& reality: A critique of corporate communications. Eastborne: Holt, Rinehart and Winston.

Brunsson, N., Rasche, A. and Seidl, D. (2012) The Dynamics of Standardization: Three Perspectives on Standards in Organization Studies, Organization Studies, vol. 33, no. 5-6, pp. 613-632.

Brunsson, N. \& Sahlin-Andersson, K. (2000). Constructing Organizations: The Example of Public Sector Reform. Organization Studies, 21(4), 721-746.

Brunsson, N., \& Jacobsson, B. (2000). A World of Standards. Oxford: Oxford University Press.

Boorstin, D. (1961). Image. A guide to pseudo-events in America. New York, NY: Atheneum.

Capriotti, P. (2009). Economic and social roles of companies in the mass media: The impact media visibility has on businesses' being recognized as economic and social actors. Business and Society, 48(2), 225-242).

Carter, S. M. (2006). The Interaction of Top Management Group, Stakeholder, and Situational Factors on Certain Corporate Reputation Management Activities*. Journal of Management Studies, 43(5), 1145-1176. 
Cillessen, A. H. N., \& Rose, A. J. (2005). Understanding Popularity in the Peer System. American Psychology Society, 14(2), 102-105.

Clegg, Stewart R., Kornberger, Martin, \& Rhodes, Carl. (2004). Noise, Parasites and Translation: Theory and Practice in Management Consulting. Management Learning, 35(1), 31-44.

Coleman, J. S. (1990). Foundations of Social Theory. Cambridge, MA: Harvard University Press.

Coombs, W. T., \& Holladay, S. H. (2010). PR strategy and application. Managing influence. Malden, MA: Wiley-Blackwell.

Davis, S. (2005). Presidential Campaigns Fine-tune Online Strategies. Journalism Studies, 6(2), 241244.

Davis, A. (2005). Media Effects and the Active Elite Audience: A Study of Media in Financial Markets. European Journal of Communications, 20(3), 303-326.

Deeds, D. L., Mang, P. Y., \& Frandsen, M. L. (2004). The influence of firms' and industries' legitimacy on the flow of capital into high-technology ventures. Strategic Organization, 2(1), 9-34.

Deephouse, D. L., \& Carter, S., M. (2005). An Examination of Differences Between Organizational Legitimacy and Organizational Reputation*. Journal of Management Studies, 42(2), 329-360.

Deephouse, D. (1997). The effect of financial and media reputations on performance. Corporate Reputation Review, 1(1/2), 68-72.

Deephouse, D. (2000). Media reputation as a strategic resource: An integration of mass communication and resource-based theories. Journal of Management, 26(6), 1091-1112.

Deephouse, D. L., \& Suchman, M. (2008). Legitimacy in Organizational Institutionalism.

DiMaggio, P. J., \& Powell, W. W. (1983/1991). The Iron Cage Revisited: Institutional Isomorphism and Collective Rationality in Organizational Fields. In W. W. Powell \& P. J. DiMaggio (Eds.), The New Institutionalism in Organizational Analysis (pp. 63-82). Chicago: The University of Chicago Press.

Elsbach, K. D., \& Kramer, R. M. (1996). Members' Responses to Organizational Identity Threats: Encountering and Countering the Business Week Rankings. Administrative Science Quarterly, 41(3), 442-476.

Elsbach, K. D. (2006). Organizational perception management. Lawrence Erlbaum.

Elsbach, K. D. (1994). Managing Organizational Legitimacy in the California Cattle Industry: The Construction and Effectiveness of Verbal Accounts. Administrative Science Quarterly, 39(1), 57-88. 
Espeland, W., \& Stevens, M. (1998). 'Commensuration as a social process'. Annual Review of Sociology, 24(1): 313-43.

Espeland, W., \& Sauder, M. (2007) "Rankings and reactivity: How public measures recreate social worlds". American Journal of Sociology 113/1: 1-40.

Fombrun, C., \& Shankey, M. (1990). What's in a name? Reputation building and corporate strategy. Academy of Management Journal, 33(2), 233-258.

Fombrun, C., \& Van Riel, C. (2004). Fame and fortune. Upper Saddle River, NJ: Financial Tiems/Prentice Hall.

Fombrun, C., \& van Riel, C. (1997) “The reputational landscape”. Corporate Reputation Review 1/1: 5-13 and 1/2: 5-13.

Gaines-Ross, L. (1997). Leveraging corporate equity. Corporate Reputation Reivew, 1(1/2), 51-56.

Gibson, R., \& Römmele, A. (2001). Changing Campaign Communications: A Party-Centered Theory of Professionalized Campaigning. The Harvard International Journal of Press/Politics, 6(4), 31-43.

Gioia, D. A., Schultz, M., \& Corley, K. G. (2000). Organizational identity, image, and adaptive instability. The Academy of Management Review, 25(1), 63-81.

Grinin, L. (2009). 'People of Celebrity' as a New Social Stratum and Elite.

Grunig, J. E., \& White, J. (1992). The effect of worldviews on public relations theory and practice. In J.E. Grunig (Ed.), Excellence in public relations and integrated communications. (pp. 34-59). Hillsdale, NJ: Lawrence Erlbaum.

Grünberg, J. \& J. Pallas (2013) Outside the newsdesk - the embeddedness of business news. Media Culture \& Society.

Hannan, M. T., \& Carroll, G. R. (1992). Dynamics of organizational populations: Density, legitimation, and competition. Oxford. Oxford University Press.

Hatch, M. J. (2008). Corporate branding. In S. R. Clegg \& J. R. Bailey (Eds.), International encyclopedia of organizational studies (pp. 283-286). Thousand Oaks, CA. Sage.

Henderson, P. W., \& Cote, J. A. (1998). Guidelines for Selecting or Modifying Logos. Journal of Marketing, 68(April), 14-30.

Higgins, W. \& Hallström, K. (2007). Standardization, Globalization and Rationalities of Government. Organization, 14(5), 685-704.

Hillygus, D. S., \& Shields, T. G. (2009). The persuadable voter: wedge issues in presidential campaigns. Princeton, NJ: Princeton University Press.

Joachimsthaler, E., \& Aaker, D. (1997). Building Brand Without Mass Media. Harvard Business Review, January-February, 39-50. 
Kennedy, M. T. (2008). Getting counted: Markets, media, and reality. American Sociological Review, 73(2), 270-295.

Kent, R. J., \& Machleit, K. A. (1990). The differential effects of within-brand and between-brand processing on the recall and recognition of television commercials. Journal of Advertising, 19(2), 4-14.

Lamont, M. (2012). Toward a Comparative Sociology of Valuation and Evaluation. Annual Review of Sociology, 38, 201-221.

Lawson-Borders, G. (2005). Blogs in Campaign Communication. American Bebavioral Scientist, 49(4), 548-559.

Lees-Marshment, J. (2008). Political marketing and British political parties (2ed.). Manchester, UK: Manchester University Press.

Lin, C. A. (2011). Communicator in Chief: How Barak Obama Used New Media Technology to Win the White House. Journal of Broadcasting \& Electronic Media, 55(2), 271-272.

L'Etang, J. (2006). Public Relations. Concepts, Practice and Critique. London: SAGE.

Manheim, J. B. (2011) Strategy in information and influence campaigns. How policy advocates, social movements, insurgent groups, corporations, governments and others get what they want. Ney York, NY: Routledge.

Mantonakis, A. (2012). A brief Pause between a tagline and brand increases brand name recognition and preferences. Applied Cognitive Psychology, 26, 61-69.

Marshall. P. D. (1997). Fame in contemporary culture. Minneapolis, MN: University of Minnesota Press.

Martins, L. (2005) "A model of the effects of reputational rankings on organizational change". Organization Science 16/6: 701-720.

Mazza, C. (1997). The Popularization of Business Knowledge: From Academic Knowledge to Popular Culture? In J. L. Alvarez (Ed.), The Diffusion and Consumption of Business Knowledge (pp. 164181). London: MacMillan Press Ltd.

Meyer, J. W., \& Rowan, B. (1977/1991). Institutionalized Organizations: Formal Structure as Myth and Ceremony. In W. W. Powell \& P. J. DiMaggio (Eds.), The New Institutionalism in Organizational Analysis (pp. 41-62). Chicago: The University of Chicago Press.

Monaco, J. (1978). Celebrity: The Media as Image Makers. New York, NY: Delta.

Nord, L. W., \& Strömbäck, J. (2009). Marketing with a feeling: The brand new party Junilistan in the Swedish European Parliamentary election 2004. Journal of Political Marketing, 8(1), 3545.

Ormrod, R. P. (2005). A conceptual model of political market orientation. Jorunal of Nonprofit and Public Sector Marketing, 14(1/2), 47-64. 
Ormrod, R. P. (2007). Political market orientation and its commercial cousin: Close family or distant relatives?. Journal of Political Marketing, 6(2/3), 69-90.

Ormord, R. P., \& Henneberg, S. C. M. (2010). An investigation into the relationship between political activity levels and political market orientation. European Journal of Marketing, 44(3/4), 382-400.

Pallas, J. \& L. Wedlin (2013) "Organization and governance of science in Mediatized Society" in: Drori, G., M. Höllerer \& P. Walgenbach (eds.) Organizations and managerial ideas: Global themes and local variations. New York, Routledge.

Parker, B. T. (2012). Candidate brand equity valuation: A comparison of U.S. presidential candidates during the 008 primary election campaign. Journal of Political Marketing, 11(3), 208-230.

Pfeffer, J. \& Salancik, G. R. (1978). The External Control of Organizations: A Resource Dependency Perspective. New York, N.Y.: Harper \& Row Publishers.

Pollock, T. G., \& Rindova, V. P. (2003). Media Legitimation Effects in the Market for Initial Public Offerings. Academy of Management Journal, 46(5), 631-642.

Power, M. (1997). The Audit Society: Oxford University Press.

Power, M. (2007). Organized uncertainty : designing a world of risk management. Oxford: Oxford University Press.

Power, M, Scheytt, T., Soin, K., \& Sahlin, K. (2009). Reputational Risk as a Logic of Organizing in Late Modernity. Organization Studies, 30(2-3), 301-324.

Rao, H. (1994). The Social Construction of Reputation: Certification Contests, Legitimation, and the Survival of Organizations in the American Automobile Industry: 1895-1912. Strategic Management Journal, 15(S1), 29-44.

Rindova, V. P., Poloock, T. G., \& Hayward, M. L. A. (2006). Celebrity firms: The social construction of market popularity. Academy of Management Review, 31(1), 50-71.

Rojek, C. (2001). Celebrity. London: Reaktion Books Ltd.

Ruef, M., \& Scott, W. R. (1998). A multidimensional model of organizational legitimacy: Hospital survival in changing institutional environments. Administrative Science Quarterly, 877-904.

Sauder, M. (2008). 'Interlopers and field change: the entry of the US news into the field of legal education'. Administrative Science Quarterly, 53(2): 209-234.

Scott, W. Richard. (2001). Institutions and Organizations. London: Sage.

Scott, B. A., \& Judge, T. A. (2009). The popularity Contest at Work: Who Wins, Why, and What Do They Receive? Journal of Applied Psychology, 94(1), 20-33. 
Strathern, M. (1996). "From Improvement to Enhancement: An Anthropological Comment on the Audit Culture." Cambridge Anthropology 19:1-21.

Suchman, M. C. (1995). Managing Legitimacy: Strategic and Institutional Approaches. Academy of Management Review, 20(3), 571-610.

Ströbäck, J. (2007). Political Marketing and Professionalized Campaigning. Journal of Political Marketing, 6(2), 49-67.

Taylor, C. (1994). Multiculturalism: Examining the Politics of Recognition. Princeton, NJ: Princeton University Press.

Turner, G. (2004). Understanding Celebrity. London, UK: SAGE Publications. Washington, M., \& Zajac, E. J. (2005). Status evolution and competition: Theory and evidence. Academy of Management Journal, 48, pp. 282-296.

Weber, M. (1946/1922). Class, status, party (pp. 180-195) in From Max Weber Essays in Sociology, ed H. H. Gerth \& C. Wright Mills. New York, NY: Oxford University Press.

Wedlin, L. (2011) Going Global: Rankings as rhetorical devices to construct an international field of management education, Management Learning, vol. 42, no. 2, pp. 199-218.

White, J., \& De Chernatony, L. (2002). New labour. Journal of Political Marketing, 1(2-3), 45-52. 